\title{
EL VIAJE DE RAFAEL HITLODEO: LA ESCRITURA DE UTOPÍA EN SU CONTEXTO
}

\author{
Manuel Rivero Rodríguez \\ (Universidad Autónoma de Madrid-IULCE)
}

\section{RESUMEN}

En la primera traducción castellana de Utopía, realizada en 1637, no se publicó el prólogo de Rafael Hitlodeo al libro primero. En dicho texto se mencionan sucesos acaecidos en los meses que preceden a la muerte de Fernando el Católico. La misión diplomática, en la que participa el supuesto autor del discurso, existió y permitió un intenso intercambio epistolar entre un grupo de humanistas integrado entre los Países Bajos, Inglaterra y Francia, Erasmo, Tunstall, Egidio y el propio Moro. Utopía se inscribe en una campaña de opinión coordinada por Erasmo y Moro, Utopía se lee o debe leerse con Instituta Principis Christiani puesto que los dos autores lo concibieron así, si bien nunca se han publicado y comentado conjuntamente. Es un momento decisivo para la Historia europea porque los humanistas imperiales, asociados a los reyes, propusieron un espacio político dominado por reyes propietarios de estados, mientras que los erasmistas concibieron estados que podían funcionar sin príncipes.

PALABRAS CLAVE: Utopía, Erasmo de Rotterdam, Tomás Moro, humanismo político, republicanismo cívico.

\section{THE JOURNEY OF RAPHAEL HYTHLODAEUS: THE WRITING OF UTOPIA IN ITS CONTEXT}

\begin{abstract}
The first translation of Utopia into Spanish was made in 1637. In that edition the prologue of Rafael Hitlodeo was not published in the first book. It mentioned events that occurred before the death of Ferdinand the Catholic. The fictional author of the speech, participated in a diplomatic mission that really existed. During his embassy, there were many letters between humanists of the Netherlands, England and France. The most important were Erasmus, Tunstall, Giles and Thomas More. Utopia
\end{abstract}


was carried out in a coordinated campaign of opinion by Erasmus and More. So, Utopia must be read in that context, with Instituta Principis Christiani. The two authors conceived their books in a complementary way, although it has never been published and discussed together. It was a defining moment for the European History because imperial humanists, associated with the kings, proposed a political space dominated by king's owners of states, while the erasmian conceived states that could operate without princes.

KEYWORDS: Utopia, Erasmus of Rotterdam, Thomas More, political humanism, civic republicanism.

En la primera traducción castellana de Utopía, realizada en 1637, no se publicó el prólogo de Rafael Hitlodeo al libro primero. En dicho texto se mencionaban sucesos acaecidos en los meses que preceden a la muerte de Fernando el Católico. La misión diplomática, en la que participa el supuesto autor del discurso, existió y permitió un intenso intercambio epistolar entre un grupo de humanistas integrado entre los Países Bajos, Inglaterra y Francia, Erasmo, Tunstall, Egidio y el propio Moro. Utopía se inscribe en una campaña de opinión coordinada por Erasmo y Moro, debe leerse con Instituta Principis Christiani puesto que los dos autores lo concibieron así, si bien nunca se han publicado y comentado conjuntamente. Esta campaña respondía a otra orquestada por los consejeros de los príncipes, Cranmer respecto a Enrique VIII, Seyssel respecto a Francisco I y Gattinara respecto a Carlos II de Borgoña (el futuro emperador Carlos V que Hitlodeo menciona como príncipe de Castilla) para construir una Europa donde la Monarquía era la única forma legítima de gobierno. Es un momento decisivo para la Historia europea porque los humanistas imperiales, asociados a los reyes, proponen un espacio político dominado por reyes propietarios de estados, mientras que los erasmistas conciben estados que pueden funcionar sin príncipes, un modelo republicano. La correspondencia de Erasmo y Moro es conocida porque fue publicada por Allen a comienzos del siglo XX, no así los documentos y las ideas de la otra parte, que constituyen la novedad de este trabajo, conservados en la sección de manuscritos de British Library y en el Archivio di Stato di Vercelli. En los manuales se ha contrapuesto el príncipe de Maquiavelo con el príncipe cristiano de Erasmo, pero la realidad es que esta confrontación no existió, Maquiavelo no era el adversario sino el sistema monárquico que estaba constituyéndose como forma política predominante en Europa, siéndolo hasta la Revolución Francesa. La, en aparente, inocente supresión del prólogo en 1637 indica que Utopía discurrió como obra de entretenimiento, descontextualizada como una ligera fantasía, una obra de creación de un hombre ingenioso. 


\section{LA COYUNTURA DE 1516}

En el estudio introductorio a la edición de Utopía que hicieron Logan y Adams para la colección ideas in context de la Universidad de Cambridge, ambos editores se preguntaban porqué escribió Moro sobre una república imaginaria, "a flawed Commonwealth". A su juicio, esto era una de las cosas que hacían que la obra fuera enigmática y creían que no se encontraría nunca una respuesta satisfactoria respecto al porqué de la obra y que pretendía Moro con ella ${ }^{1}$.

El texto introductorio, relacionado con los motivos por los que Moro se encuentra con Hitlodeo, señala un viaje diplomático en el que figuran personas y lugares que dan cuenta del contexto en el que se produjo. Gracias a las investigaciones de Hexter sabemos que Utopía fue concebida en el verano de 1515, entre el 21 de julio y el 21 de octubre. Moro viajó a Bruselas, donde conoció a Peter Giles (Pedro Egidio) quien supuestamente participó en la conversación con Hitlodeo. Para Logan y Adams las citas a Giles indican que los contenidos del diálogo evocan elípticamente a conversaciones que ambos humanistas tuvieron en Bruselas empleando guiños y claves que solo ellos conocían, esa segunda lectura nunca podrá conocerse a menos que se encuentren documentos desconocidos que salgan a la luz revelando esa discusión ${ }^{2}$.

Moro escribió en 1515 la segunda, mientras que la introducción la escribió un año después en 1516, cambiando el significado y el alcance de la primera versión o borrador de la obra. Al añadir la primera parte y llevar la obra a la imprenta Moro le dio un significado político claro, con una intencionalidad que expresa en el título "On the best state of the Commonwealth" con referencias directamente tomadas de Platón y Aristóteles. Como ha señalado Quentin Skinner, al añadir esta parte introductoria el autor ponía el foco en el gobernante, el príncipe y en cómo ha de gobernar. A su juicio Moro escribía en su condición de consejero de Enrique VIII proponiendo que Utopía bien puede interpretarse, tras su transformación, en un espejo de príncipes ${ }^{3}$.

Nuestra contribución no pretende despejar la clave del porqué de Moro pero sí aportar información siguiendo una recomendación de Skinner que nos parece muy pertinente «if we are to write de history of ideas in a properly historical style, we need to situate the texts we study within such intellectual contexts and frameworks of discourse as enable us to recognise what their authors were doing in writing them» ${ }^{4}$. Moro sitúa la conversación con el marino Hitlodeo en un momento muy significativo, las conversaciones de paz que mantiene Enrique VIII con Carlos de Borgoña, aún

\footnotetext{
1 Thomas More, Utopia, ed. George M. Logan y Robert M. Adams (Cambridge: Cambridge University Press, 2002), vii-xxx.

${ }^{2}$ More, Utopia, vii-xxx; Jack H. Hexter, More's Utopia: The Biography of an Idea, 1 st edn (New York: Harper \& Row, 1965).

${ }^{3}$ Quentin Skinner, Los Fundamentos Del Pensamiento Politico Moderno (Madrid: Fondo de Cultura Económica, 1985), I, 239-76.

${ }^{4}$ Quentin Skinner, Visions of Politics. Volume 1, Regarding Method (Cambridge: Cambridge University Press, 2002), vii.
} 
príncipe de Castilla pero soberano de los Países Bajos desde el 5 de enero de dicho año. Las conversaciones reforzarían la amistad anglo-borgoñona, asentada durante la guerra de los Cien años además de los tratos comerciales que establecieron las legaciones ratificando acuerdos entre los soberanos de ambos lados del canal de la Mancha.

Los hechos que acompañan y jalonan la redacción del libro, concretamente en los Países Bajos y Bruselas sitúan la acción que enmarca el diálogo en que se da cuenta del descubrimiento de Utopía en un momento crucial de la historia política de Europa. Utopía salió de la prensa de Lovaina en diciembre de 1516. El opúsculo latino se difundiría en un momento y un lugar en el que había un intenso y acalorado debate político relativo al futuro de los Países Bajos y de Europa.

Mercurino Arborio di Gattinara, residente en Bruselas y espectador privilegiado de dichos cambios, advirtió que los acontecimientos que jalonaron los años 1515 a 1517 en la Corte de los Países Bajos podrían describirse como una lucha entre el bien y el mal, como un momento decisivo que solventó la suerte de la Cristiandad $^{5}$. Esa apreciación de quien entonces era consejero del emperador Maximiliano I, situaba a Moro y Erasmo en el lado del mal considerando que las ideas que defendían llevarían a la disolución de la Cristiandad. En 1506 la muerte del duque de Borgoña, Felipe el Hermoso, frustró un primer intento de unión entre los Países Bajos y Castilla. Muchos de los consejeros del príncipe Carlos vivieron aquella experiencia en el séquito de su padre. Para quienes viajaron a España la experiencia fue ingrata, fueron despojados de sus joyas y sus bienes y señala el cronista Laurent Vital que volvieron casi desnudos. Así mismo, para los neerlandeses la ausencia de su príncipe resultó dura, acostumbrados como estaban a tener a su soberano en el país arbitrando litigios y administrando justicia. Acudir a un reino lejano y no poder comunicar con el soberano debilitó a la Corte y a los ministros del gobierno por lo que no se deseaba que los duques de Borgoña volvieran a viajar al extranjero. Con la muerte del duque Felipe, el emperador Maximiliano I abuelo y tutor de Carlos, el heredero, entregó la regencia de los Países Bajos a su hija la duquesa Margarita de Saboya, que en 1507 instaló su Corte en Malinas. Era importante que la regente educase al príncipe hasta que cumpliese su mayoría de edad. Carlos crecería lejos de su madre Juana I de Castilla, declarada demente y debía ser educado para heredar un inmenso patrimonio, que incluía el Imperio alemán, el reino de Bohemia, el archiducado de Austria, los Países Bajos, la Borgoña condal, las coronas de Castilla y Aragón junto a los reinos italianos de Nápoles, Sicilia y Cerdeña. Mientras vivieran los abuelos de Carlos, el emperador Maximiliano I y Fernando el Católico, dicha unión no se produciría pero la inminencia de la sucesión marcaba el futuro de todos los europeos ${ }^{6}$.

\footnotetext{
${ }^{5}$ Disertación de Mercurino Arborio di Gattinara presentada a la Corte de la regente Margarita de Saboya, sd. 1516, Archivio di Stato di Vercelli, Famiglia Arborio Gattinara, mazzo 6 -11 (en lo sucesivo ASV. FAG.).

${ }^{6}$ James Tracy, Holland under Habsburg Rule, 1506-1566: The Formation of a Body Politic (Berkeley: University of California Press, 1990).
} 
El lugar donde la resistencia a la futura unidad dinástica de Europa bajo la Casa de Habsburgo fue más intenso fue precisamente en la Corte de Borgoña, los nobles y magnates de los Países Bajos y de Franco Condado temían perder su autonomía e independencia a favor de los intereses particulares de la casa de Habsburgo. Conforme se acercaba la mayoría de edad del príncipe un reducido grupo de nobles y magnates borgoñones logró aislarlo. El gobierno de la regente Margarita se volvió contra Maximiliano I, el Consejo de Borgoña rechazaba el excesivo peso de la tutela imperial, en la Casa del príncipe heredero se encontraban sus principales detractores, encabezados por el Canciller de Brabante Jean le Sauvage y Guillermo de Croy.

Por tal motivo Maximiliano I impuso en 1511 la inclusión de hombres leales a su persona en el consejo de regencia. Así logró que un abogado piamontés, de su entera confianza, Mercurino Arborio di Gattinara, fuera nombrado presidente del parlamento de Dôle. Pero la regente no lo quiso consigo en Malinas, obligándolo a residir en el Franco Condado haciéndole la vida imposible por medio del mariscal de Vergy. No quería consejeros de la Casa de Habsburgo. El cariz que tomaba el asunto llevó a Maximiliano a anunciar su viaje a los Países Bajos y al Franco Condado para tomar directamente las riendas del poder, pero hubo de aplazarlo por la falta de cooperación del gobierno de regencia y la amenaza de una revuelta. Así mismo la regente se negó a organizar la Casa del príncipe Carlos según le había indicado su padre, insistiendo en colocar como consejeros del heredero a las personas que a ella mejor le parecieron. Pero el emperador no quería ceder, en 1513 propuso a Gattinara para presidir el Consejo Privado, pero el puesto lo obtuvo Jean Le Sauvage, que desde entonces le fue profundamente hostil ${ }^{7}$. En este ambiente los leales al emperador fueron perseguidos y hubieron de refugiarse o irse al exilio. La violencia entre partidarios del gobierno de regencia y del emperador Maximiliano llegó a su clímax en 1514, ese año Gattinara sobrevivió a varios intentos de asesinato. En viaje hacia Flandes, para rendir cuentas a la Corte de Malinas, su comitiva fue asaltada de noche por un contingente armado y ya ante el Gran Consejo de Malinas fue procesado y condenado el 26 de octubre de 1515 por malversación y abuso de poder. Fue desposeido y despojado de sus cargos, títulos y rentas, incluyendo la presidencia de Dôle. Ante la inseguridad y las amenazas contra vidas y haciendas, muchos servidores del emperador se refugiaron en sagrado, Gattinara lo hizo en la cartuja de Santa María de Bruselas ${ }^{8}$.

\section{EL PRÍNCIPE PADRE O EL PRÍNCIPE MONARCA}

A veces solemos olvidar que el título completo de Utopía refleja un juicio y una idea «Dē Optimo Rēpūblicae Statu dēque Nova Insula Ütopia» (Del estado ideal de una república en la nueva isla de Utopía). La cuestión principal que aborda el tratado

\footnotetext{
${ }^{7}$ Minuta de carta de Margarita de Austria al emperador Maximiliano, s.d. 1513, en Joseph Le Glay, Correspondance de l'empereur Maximilien 1er et de Marguerite d'Autriche de 1507 à 1519 (París: Jules Renouard, 1839), II, 243.

${ }^{8}$ Manuel Rivero, Gattinara, Carlos V y el sueño del Imperio (Madrid: Sílex, 2005).
} 
es la dimensión espacial de la autoridad y no sólo en términos geográficos (como puede apreciarse en las ilustraciones del frontispicio de la primera y segunda ediciones o en la interpretación visual del cartógrafo Hortelius según su particular lectura del tratado). Aborda la cuestión del buen gobernante y del buen gobierno siguiendo el principio doméstico de la Oeconomica, un rey es ante todo como un padre de familia: «Un Príncipe, bien lo sabéis, es como una fuente de la que manan perennemente sobre su pueblo todos los bienes y todos los males».

El discurso moral gira alrededor de la Corte del príncipe, el lugar que determina si lo que fluye es bueno o no, pero hay un motivo insistente a lo largo del discurso, todo gobierno para ser bueno ha de eliminar toda aspiración expansiva: «No hay en mí la habilidad que vos me atribuís, y aunque la hubiese y yo mismo turbase mi propio sosiego, no serviría para los negocios de Estado. En primer lugar, a las gentes divierten más los hechos bélicos y caballerescos que las cosas de la paz, y más se preocupan de conquistar, por buenas o malas artes, nuevos territorios que de gobernar pacíficamente los que ya tienen». Y más adelante: «Y ahora digo yo: ante tan graves e importantes negocios, ante tantos nobles y prudentes varones que solamente aconsejan al Rey que hablen las armas, o sea la guerra, ¿qué sucedería si mi humilde persona se levantase y les aconsejase que cambiasen el rumbo? Yo les diría: Dejad tranquila a Italia y quedaos en casa; el reino de Francia es tan grande que un solo hombre no puede gobernarlo bien, y el Rey no ha de menester engrandecerlo más».

No muy diferentes son los argumentos de Erasmo. Esto se acusa particularmente en su crítica acerba a la política dinástica, al amontonamiento de estados muy diversos en manos de un solo príncipe, desaconsejando con firmeza la posesión de territorios geográficamente alejados unos de otros (capítulo IX: "Las alianzas matrimoniales de los príncipes"). Lo cual no es más que el desarrollo de una idea directriz enunciada en la dedicatoria escrita al príncipe: «naciste para un imperio hermosísimo y destinado a otro mayor, de modo que (...) quizás tú debas trabajar para ceder alguna porción de tus dominios antes de ocuparlos». La necesidad de ceder patrimonio en aras de un bien superior, la paz, se repite y extiende de forma pormenorizada al final de la obra, insistiendo en que la salvaguarda de la misma debe llegar incluso a la renuncia del derecho (capítulo XI).

No se trata de coincidencias sino de textos escritos a la vez y con carácter complementario. Es conocida la amistad entre ambos humanistas y se suele señalar el doble significado del Elogio de la Locura como elogio de Moro (Morias Enkomion). Más allá de esa complicidad, en este caso concreto, Moro y Erasmo cruzaron correspondencia y compulsaron sus respectivos manuscritos pues ambos perseguían el mismo objetivo, unidos por una causa común y en un momento que comprendían decisivo ${ }^{9}$. Sus textos apuntaban hacia un grave problema, la deriva tiránica de los

9 A.G. Dickens y W.R.D. Jones, Erasmus the Reformer (London: Methuen, 2000), 98-136; Johan Huizinga, Erasmo (Barcelona: Salvat, 1989), 269-82; Cornelis Augustijn, Erasmo de Rotterdam: Vida y obra (Barcelona: Crítica, 1990), 80-99. 
estados europeos. Las "nuevas monarquías" se estaban edificando sobre principios autoritarios ignorando el carácter de servicio que debían los príncipes a los súbditos. Lo hacían no como una reflexión abstracta sino espoleados por un presente que querían cambiar, por acontecimientos inmediatos que afectaban a su existencia y la de sus contemporáneos. En el triángulo formado por Francia, Borgoña e Inglaterra, extendido hacia Castilla y Alemania, el régimen monárquico era una realidad consolidada tras cruentas guerras civiles, las dinastías Valois, Tudor, Habsburgo o Trastamara se habían impuesto, estando legitimadas por un derecho sucesorio no cuestionado y por la sacralización del linaje real. La superación de las guerras civiles por medio de la solución dinástica, si bien había traído la paz, también había abierto nuevos problemas siendo el principal la consideración del reino como propiedad del soberano al tiempo que comunidad política ${ }^{10}$.

La pretensión del emperador Maximiliano de engrandecer la Casa de Habsburgo y construir sobre ella la Monarchia Universalis, era no sólo bien conocida sino que éste había insistido para que el consejo de regencia aceptase sus argumentos y seguramente Jean le Sauvage recurrió a los humanistas para hacer frente a sus argumentos ${ }^{11}$. Las preocupaciones de Moro al describir "el estado ideal de una república" y los motivos por los que Erasmo redactó su obra no son ajenos a esto. Erasmo fue nombrado consejero en marzo, en junio entregaba su tratado a la imprenta, en septiembre se instaló en Bruselas y no abandonó la Corte hasta febrero de $1517^{12}$. Le Sauvage y Erasmo eran viejos amigos y su colaboración se remontaba al año 1514, no estando muy lejos el uno del otro en los duros años en los que el partido borgoñón se hizo con el control del gobierno de regencia ${ }^{13}$. La misión de redactar un manual que sirviese para fijar los límites del soberano, sus obligaciones y sus deberes era la parte visible de una intensa campaña de opinión que requería mucha más energía que la efectuada durante la declaración de la mayoría de edad del príncipe Carlos ${ }^{14}$. A su vez, en agosto de 1516 Moro se instaló en Amberes como embajador del rey de Inglaterra ante el rey de Castilla, manteniéndose muy cercano al nuevo consejo ducal, al partido inglés (no olvidemos que desde la Guerra de los Cien Años este grupo fue fundamental en la política inglesa respecto a Francia). Es la muerte de Fernando el Católico y la nueva condición del duque de Borgoña como soberano de España lo que justifica una

\footnotetext{
${ }^{10}$ Kenneth Pennington, The Prince and the Law, 1200-1600: Sovereignty and Rights in the Western Legal Tradition (Berkeley: University of California Press, 1993), 202.37; Walter Ullmann, Principios de

gobierno y politica en la Edad Media, ed. by Graciela. Soriano de García-Pelayo (Madrid: Alianza Editorial, 1985), 197-211.

${ }^{11}$ Carta de Maximiliano I a Margarita de Austria, II, 321.

12 Augustin Renaudet, Préréforme et Humanisme à Paris pendant les premières guerres d'Italie: 1494-1517 (Ginebra: Slatkine, 2011), 241-274.

${ }^{13}$ En el verano de 1514 Erasmo residió en Gante invitado por Le Sauvage. El Canciller fue descrito por el humanista como «virum in omni literarum genere doctissimum», fraguando una sólida amistad y, según los editores de la correspondencia erasmiana, halló un «liberal patron». Vid. Erasmo de Rotterdam, Opus Epistolarum / The Complete Letters of Erasmus, ed. Stanford Allen (Oxford: Clarendon, 1906), vol. 2, cartas 301 (p. 6), 410 (pp. 239-240) y 412 (pp. 411-412).

${ }^{14}$ Jean Le Sauvage a Erasmo, Bruselas 8 de julio de 1516, Erasmo de Rotterdam, Opus Epistolarum, vol. $2 \mathrm{n}^{\circ} 436$ (pp. 276-277).
} 
representación un tanto aventurada, pues aún se mantenía que la reina de Castilla era Juana $\mathrm{I}^{15}$.

Tanto el príncipe ideal de Moro como el de Erasmo, se caracteriza por poseer un dominio tranquilo, legitimado por su sangre (por eso ni siquiera concibe que deba ser temido para ser obedecido); ha de ser como un padre para sus súbditos, ha de preferir vivir con ellos, sin ambicionar poseer más tierras o gobernar a otros. Un soberano que vive con y para la comunidad, que ha de descartar la ambición militar (portadora de sufrimiento y desestabilización de la tranquilidad pública) como también debe renunciar si fuera necesario a heredar demasiados estados pues estorbaría la comunicación con sus súbditos o con sus vasallos. En el caso de Erasmo el mensaje era claro, el duque de Borgoña debería saber deshacerse de un puñado de posesiones antes de que sus obligaciones con otros lo alejasen, lo extrañasen y lo convirtieran en un mal gobernante (como el padre que abandona a sus hijos). Instituido para servir al pueblo, era la cabeza de la comunidad, concluyendo sin asomo de duda que ser cabeza de muchas repúblicas era antinatural. El buen rey, vivía con sus súbditos, los atendía personalmente, no era su propietario ${ }^{16}$.

Este ideario se inscribía en el proyecto político de los consejeros borgoñones que en 1515 habían forzado el reconocimiento de la mayoría de edad del duque Carlos, las ideas del manual daban cuerpo al sentimiento que había guiado la ruptura respecto al emperador Maximiliano I de Habsburgo. Éste, que deseaba hacer de su nieto un nuevo Carlomagno, llamado a recomponer la Universitas Cristiana, se sentía frustrado por la resistencia de los neerlandeses. Abiertamente, Erasmo exponía las razones de esa discrepancia, el temor al extrañamiento del soberano propio, de su separación respecto a su pueblo. Refutaba la idea de unidad política en un solo gobierno, defendida por los humanistas imperales, frente a cuyas tesis, Erasmo y Moro proponían guiar la política por la "Filosofía de Cristo": ya había una unidad en la fe, franceses y alemanes no eran extranjeros entre sí porque eran cristianos y compartían una patria común, la Cristiandad. Ésta solo tenía un soberano, Cristo, contemplando a los diferentes príncipes seculares como una manifestación de un poder y autoridad que sólo pertenecía a Dios, del que eran simples administradores. Para él la idea de un Imperio Universal enmascaraba un proyecto de tiranía universal.

Ciertamente esto atacaba algo concreto, nada abstracto. La Reforma Imperial (Reichsreform) emprendida por el emperador Maximiliano I proponía un modelo federativo (Reichsseinung) que no solo articulaba la diversidad interna del Imperio Alemán sino que permitiría construir una Monarquía Universal cimentada sobre la casa de Habsburgo. La polémica en la que se inscribían los textos de Moro y de Erasmo se resumían en una cuestión, la de si era posible o no gobernar muchos estados. Su opinión era que no y de ahí que sus recomendaciones fueran dirigidas a limitar un príncipe doméstico, que no buscase el matrimonio fuera del territorio, que gobernase

\footnotetext{
15 Bethany Aram, La Reina Juana: Gobierno, piedad y dinastía (Madrid: Marcial Pons, 2001).

${ }^{16}$ Dickens y Jones, Erasmus the Reformer, 100-103.
} 
con sus súbditos, viviera con ellos, y no desease más estados de los que ya poseía. La exigencia de que el rey residiera en el reino o que contrajese matrimonio con una mujer del país no era una reclamación ingenua, trataba de hacerle ver que debía renunciar a la ambición de apoderarse de más patrimonio dirigiendo su lealtad no al servicio del linaje sino de la comunidad ${ }^{17}$.

Detrás de estos argumentos, podía advertirse la ansiedad de la Corte de Borgoña que temía verse sometida a gentes extrañas procedentes de otras naciones, al tiempo que tomaba posiciones ante unos procesos sucesorios en los que sus miembros esperaban obtener grandes beneficios. La nobleza y las ciudades de los Países Bajos, veían pocas ventajas en la gloria futura que aguardaba a la casa de su príncipe si éste era coronado emperador. En dicho ambiente, no es casual que quien contrató los servicios de Erasmo, el Gran Canciller Jean le Sauvage, fuera el portavoz del partido anti imperial y quien defendiera con más vigor la idea de que Carlos II sería duque de Borgoña por y para los borgoñones, admitiendo su acceso a la corona de España como espacio para beneficiar a sus súbditos ducales ${ }^{18}$. Aquí hay una contradicción flagrante, que notó Erasmo precisamente en una carta a su amigo Tomás Moro, manifestando su pesar porque la avaricia del séquito ducal sacrificaba a los Países Bajos, abandonados por su príncipe en un sentido político ${ }^{19}$.

Erasmo no se contentó con escribir su Istituta..., «escrito siguiendo las indicaciones del Gran Canciller» Sauvage, redobló su esfuerzo y añadió más tarde otro texto polémico, violentamente anti imperial: "El escarabajo acecha al águila" (1517), un texto más agresivo, casi impropio del amable humanista, que debe leerse teniendo en cuenta la lucha de su patrocinador por evitar la salida del soberano a España a tomar posesión de nuevos estados ${ }^{20}$. Además, estos tratados políticos no solo justificaron el salario del humanista como consejero, lo comprometieron y lo expusieron a peligros que iban más allá del debate académico. Fue objeto de furibundos ataques que él mismo denunció no dirigidos contra sus ideas, sino contra su persona pues nacían de las pasiones políticas. Amenazas que partían de un enigmático grupo, los "mendicantes tiránicos" (denunciados con este festivo nombre en marzo de 1518, "Ptochoturannophilomousomachia") ${ }^{21}$. Este calificativo parece apuntar a un lugar de

17 Volker Press, "The Habsburg Court as Center of the Imperial Government", The Journal of Modern History, 58 (1986), 23-45 <http://dx.doi.org/10.1086/243147>; Beat Kümin, "Political Culture in the Holy Roman Empire", German History 27 (2009), 131-44.

${ }^{18} \mathrm{La}$ división en el consejo de regencia se produjo en 1511 al enfrentarse Le Sauvage al señor de la Roche para hacerse con el control del Consejo Privado, vid. Carta de Margarita de Austria a Maximiliano I, Gante 23 de mayo de 1511, Le Glay, Correspondance, I, 402 (véase la nota biográfica redactada por el editor que subraya los vínculos del canciller con Erasmo).

${ }^{19}$ Desiderio Erasmo, Adagios del poder y de la guerra y teoría del adagio, ed. Ramón Puig de la Bellacasa Alberola (Barcelona: Pre-Textos, 2000), 14-15.

${ }^{20}$ Erasmo a Froben sobre "Querella Pacis", julio de 1517, Erasmo de Rotterdam, Opus Epistolarum, vol. III, nº 602 (p. 13).

${ }^{21}$ Erasmo a Moro, Lovaina 5 de marzo de 1518, Erasmo de Rotterdam, Opus Epistolarum, vol. III, n ${ }^{\circ}$ 785 (p. 238). 
Bruselas, a un centro donde se encontraban refugiados en sagrado los enemigos de Le Sauvage: la cartuja de Santa María.

\section{LA IDEA IMPERIAL}

Durante el Renacimiento el humanismo político adoptó diversas formas. Habitualmente se ha identificado con el republicanismo pero hay que advertir que tanto en Italia como en el Norte de Europa la imagen de Roma como modelo a seguir siguió dos preceptos distintos, el republicano y el imperial ${ }^{22}$. No obstante en el problema concreto de la sucesión de Carlos II de Borgoña a sus reinos hispánicos y después al Imperio los modelos clásicos no se tuvieron en cuenta pesando más las tradiciones propias. Era la tradición y la costumbre el fondo del problema, por tanto los humanistas imperiales en los Países Bajos estaban muy lejos del humanismo italiano y muy cerca de la tradición milenarista occidental.

Esta singularidad la apreciamos en el caso de Mercurino Arborio di Gattinara quien, desde su refugio en la cartuja desarrolló toda una labor de persuasión y de propaganda para forzar un cambio en la Corte, era preciso que el duque embarcase rumbo a España para tomar posesión de la herencia de Fernando el Católico. Escribió un tratado político que entregó a Carlos II casi al mismo tiempo que Erasmo y Moro concluían los suyos, el primero en junio y el segundo entre septiembre y diciembre. Además, en agosto Moro se había establecido en Amberes y fue entonces cuando redactó la parte añadida a Utopía como preámbulo. El tratado de Gattinara era radicalmente distinto a los libros de Moro y Erasmo, lo había escrito en un estado de introspección espiritual, casi místico, afrontando un profundo proceso de renovación de su fe, marcado por la búsqueda a las respuestas trascendentes sobre la existencia y la salvación a través de la lectura sin desmayo de una amplia literatura religiosa, principalmente San Gregorio Magno y Joaquín de Fiore. Inmerso en sus tribulaciones, conoció el fallecimiento de Fernando el Católico y unos días o semanas después, en la soledad de su celda tuvo una experiencia que marcaría el curso futuro de su vida: «Un sueño de la futura Monarquía y triunfo de la Cristiandad en la persona del mismísimo rey (Carlos), prediciendo con varias razones que habría de ser emperador y grandísimo monarca» ${ }^{23}$. Dicho sueño acabó siendo el argumento que le animó a escribir y reflexionar sobre política. No deja de ser curioso que él, un hombre de leyes, como Erasmo y Moro, filólogos y eruditos, se veía también en la circunstancia de escribir sobre política y exponer sus ideas ${ }^{24}$.

22 Para el concepto de humanismo imperial véase Hans Baron, The Crisis of the Early Italian Renaissance: Civic Humanism and Republican Liberty in an Age of Classicism and Tyranny (Princeton, NJ: Princeton University Press, 1955), 293-303.

23 "Inventorio de le robe lassate in Bruxelles nel monestorio de nostra dama de gratie", s.d. 1517, ASV. FAG. mazzo 8.

${ }^{24}$ Este manuscrito lo encontró el profesor Headley en la British Library y su noticia me llegó por la profesora Rebecca Ardt Boone, por lo que a ambos debo agradecer su gentileza y algo más, pues me proveyeron de una copia del mismo. 
Enraizado en una perspectiva monárquica de largo recorrido, Gattinara no era un imperialista aislado, su punto de vista entroncaba con una perspectiva imperial propia de los Países Bajos, que gozaba de una cierta reputación gracias a la pluma de Georges d'Halluin, señor de Comines, Rolleghen y Rouquette, vizconde de Nieuport, que en 1514 dedicó a Carlos de Borgoña su traducción de los triunfos romanos de Tácito con el objeto de prepararle para sus futuras responsabilidades imperiales (el cual parece blanco más probable de la crítica erasmiana que Maquiavelo). Formado en la universidad de Turín, Gattinara fue discípulo de Claude de Seyssel. Entendía la política -al igual que su maestro que abandonó la universidad para servir al rey de Franciacomo ejercicio del dominio y comprendía la Monarquía Universal no solo como un medio para dotar de sentido y finalidad trascendente al ejercicio del poder, sino también como una forma de entender y gestionar la autoridad. Un soberano poseedor de muchos estados era capaz de gobernarlos bien y ser un buen padre para sus súbditos y vasallos. La Monarquía no tenía porqué significar abandono, guerra e inestabilidad ${ }^{25}$.

Gattinara compartía sus ideas en un ámbito intelectual en el que destacaba su maestro, Claude de Seyssel, consejero de Francisco I de Francia que se distinguió como catedrático de derecho y humanista, tradujo al francés la obra de Eusebio de Cesarea, Tucídides, Diodoro de Sicilia, Apiano, Jenofonte y Séneca. Autor de obras de teología como una refutación a los valdenses o la Moralis explicatio evangelii Lucae (Josse Bade 1514), de derecho como el Speculum feudorum (Basilea 1564) o Problèmes d'Appien (que refunde su pensamiento jurídico), destacó sobre todo en su defensa de la Monarquía hereditaria como fundamento de la república. En sus dos tratados principales Grand Monarchie de France (Paris 1519), De republica Galliae et regum officiis libri duo (Estrasburgo 1548) y Louanges du bon roi de France Louis douzième de ce nom (Paris 1508) aboga por la necesidad de restaurar el Imperio Cristiano, asignando a los soberanos franceses una misión "imperial" particular, por su preeminencia en el seno de la Cristiandad a la cual debían dirigir y reformar. En el fondo, esta prééminence française significaba que por debajo de Dios no existía en el mundo autoridad más grande que la del rey de Francia, según rezaba un famoso verso del poeta Joaquim du Bellay (Car rien n'est après Dieu si grand qu'un roi de France). Sus Louanges fijaron la imagen ideal de la Cristiandad bajo el signo de la unidad: Un Dios, un rey, una fe, una ley ${ }^{26}$.

Para Gattinara la necesidad de la Monarquía Universal era también evidente, si bien era la casa de Habsburgo la que debía ocupar el lugar que su maestro asignaba a la de Valois. Las analogías entre la memoria en la que Gattinara expuso su idea de Monarquía en 1516 como la más conocida del 12 de julio de 1519 y la Grand'Monarchie de France de Seyssel establecen correlaciones que, por ejemplo Moro y Erasmo ignoran, como es vincular la Monarquía Universal y Reforma de la Iglesia, su adhesión a la

${ }^{25}$ Rivero, Gattinara, 27-65.

${ }^{26}$ Ruth Mackay, "Governance and Empire during the Reign of Charles V: A Review Essay", Sixteenth Century Journal 40-3 (2009), 769-79; Gaston Zeller. "Les Rois de France candidats à l'Empire", en Aspects de la politique française sous l'Ancien Régime (París: PUF, 1964). 
espiritualidad de la observancia y su percepción de la necesidad de la unión en la jefatura de la Cristiandad (unum ovile et unum pastor, un sólo rebaño y un solo pastor). ${ }^{27}$

Estas ideas arrancaban de una antigua y acrisolada tradición milenarista común a todo el Occidente cristiano según la cual la Edad de Oro vendría en el momento en que un emperador gobernase el mundo tras unirlo bajo la fe de Cristo, instalando su trono en la Casa Santa de Jerusalén. Por otra, el "humanismo imperial" dio una nueva lectura a imágenes fuertemente arraigadas en la cultura europea. Sobre todo, permitió a la Casa de Habsburgo articular un discurso sobre la legitimidad de su aspiración al dominio universal. Más allá de un contraste entre lo que Hans Baron denominó humanismo imperial y humanismo cívico, hay sobre todo un debate en torno a la idea misma de la comunidad política, sus límites y sus fines. En este plano, la profecía joaquinista ocupaba un lugar muy importante. Así, destaca una intensa preocupación sobre la inminencia del Juicio final y la interpretación de los sueños como heraldos del destino, siendo especialmente significativo un opúsculo atribuido a Joaquín da Fiore ("Victoria de Cristo sobre el Anticristo") que Gattinara copió cuidadosamente, cuyo traslado que concluyó con un comentario de su propia cosecha acerca del curso de la Historia a la luz de la vida eterna y de la victoria sobre el Anticristo en vísperas del Juicio Final ${ }^{28}$.

Así, si volvemos nuestra mirada hacia los enunciados que definían la «futura Monarquía» que soñó Gattinara, el elemento joaquinista aflora cuando leemos el augurio de la venida de una tercera edad, la época del espíritu en la que se entraría en un tiempo de santidad previo al juicio final, vinculando a Carlos $\mathrm{V}$ con la responsabilidad de crear el Reino de Dios en la tierra. Por eso, cómo afirmara en su discurso de Zaragoza, debía coronarse emperador, «medio justísimo para conseguir todo el mundo», alcanzar la Monarquía del Mundo, la Monarcbia Universalis, y con ella la redención. Latía con fuerza la esperanza escatológica y milenarista de un monarca que restauraría el orden, que pondría fin al escándalo de la corrupción de la Iglesia (expectativas a las que, por cierto, ni siquiera fue ajeno Martín Lutero que exhortó a Carlos $\mathrm{V}$ a comportarse como un nuevo Federico II) ${ }^{29}$.

La Monarquía Universal se planteaba como «idea de Monarquía futura» y era una «idea de príncipe Cristiano» alternativa y muy alejada de lo propuesto por Erasmo y Moro. Su príncipe cristiano anteponía el deber hacia la dinastía como un mandato

${ }^{27}$ Rebecca Boone, "Claude de Seyssel's Translations of Ancient Historians', Journal of the History of Ideas 61-4 (2000), 561 <http://dx.doi.org/10.2307/3654069>; Ralph E. Giesey, "Review: The Monarchy of France. by Claude de Seyssel", Renaissance Quarterly 35-3 (1982), 490-91 $<$ http://dx.doi.org/10.2307/2861220>.

${ }^{28}$ Las notas, borradores y apuntes de lectura de Gattinara se conservan en ASV. FAG. mazzo 3, interesan particularmente dos manuscritos, un extracto y copia con comentarios autógrafos de un texto atribuido a Gioacchino da Fiore titulado "Vittoria di Cristo sull'Anticristo" el otro son impresiones, anotaciones y estractos derivados del estudio de la obra de San Gregorio Magno. Esto también lo menciona en sus memorias, véase Carlo Bornate, "Historia Vitae et Gestorum per Dominum Magnum Canellarium, Con Note, Aggiunte E Docu- Menti", Miscelanea di Storia Italiana 48 (1915), 233-558.

${ }^{29}$ Martín Lutero, Escritos Políticos, ed. Joaquín Abellán (Madrid: Tecnos, 1986), 36. 
divino, expresando como principal obligación del soberano el cumplimiento de las disposiciones de sus antecesores que eran la expresión misma de la voluntad de Dios. Ésta había dispuesto que fuera el principal monarca de la Cristiandad, siendo su deber señorearla y defenderla. Las razones políticas (poder, honor y gloria), o las obligaciones con los súbditos estaban subordinadas al servicio de un bien superior que era la paz universal, ganada no a través de la renuncia sino de la posesión de una autoridad que daría lugar a la Monarquía del Mundo, dando curso a una Nueva Edad de Oro en la que se produciría la segunda venida de Cristo a la Tierra. En tales circunstancias la guerra no sólo era lícita, sino que constituía una obligación necesaria. Es decir, defendía a ultranza la continuidad en Carlos de la política ancestral de la Casa de Habsburgo.

Sin embargo cuando el soberano embarcó camino de España, esto no significó que asumiera su misión imperial. Gattinara hubo de huir de los Países Bajos siendo acogido en el servicio del duque de Saboya. La idea imperial no estaba en la agenda de la Corte. El discurso anti dinastista del círculo de Jean le Sauvage había logrado desligar a la Corte de Borgoña de los intereses de la Corte Imperial. Pero había una profunda contradicción, puesto que no se renunció a la incorporación de los reinos de España al patrimonio del duque Carlos, dado que entrañaba un claro beneficio para sus súbditos flamencos (que confiaban en acaparar cargos, riquezas y dignidades de aquellas tierras). Por eso, cuando se conoció la decisión definitiva del príncipe Carlos de ponerse en camino para jurar como rey ante las cortes de las coronas de Castilla y Aragón los escritos de unos y otros comenzaron a circular por la Corte $^{30}$.

\section{¿TRIUNFO DE LA IDEA IMPERIAL?}

Hemos de considerar que Utopía se gestó en medio de un intenso debate político, en el que sus participantes se jugaban mucho y sentían que aquel momento era decisivo, siendo el final de un proceso histórico que arrancaba de mucho tiempo atrás y que tampoco se zanjó con la marcha de la Corte de Carlos II de Borgoña a España, abandonando los Países Bajos. Se mantuvo cuando el duque se coronó rey, como Carlos I de Castilla y Aragón terminando por ser también Carlos V de Alemania, Sacro Romano Emperador. La tensión entre imperiales y antiimperiales cambió de signo durante el viaje de la Corte por tierras españolas, la soledad de los flamencos en Castilla y Aragón les hizo comprender que sin la ayuda imperial su señor no lograría afianzar su dominio en aquellos reinos, la hostilidad de los españoles y la mala voluntad del rey Francisco I de Francia llevaron a modificar sus posiciones de partida. Maximiliano les hizo ver que si el soberano francés se hacía con la dignidad imperial peligraría incluso la integridad de los Países Bajos y el Franco Condado por las aspiraciones de la casa de Valois por hacerse con toda la vieja Borgoña ducal. El único consejero que resistía las presiones y se negaba rotundamente a aceptar la política imperial era el Gran Canciller Jean Le Sauvage, el más firme partidario de la alianza

\footnotetext{
30 Sobre los acontecimientos de 1517, vid. "Vita del Gran Cancelliere", fols. 24-27 en ASV. FAG. mazzo 3. Paul Rosenfeld, "The Provincial Governors from the Minority of Charles V to the Revolt", Anciens Pays et Assemblées d'État 17 (1959), 3-63; Bornate, "Historia Vitae", 267-269.
} 
con el soberano francés, el cual falleció oportuna e inesperadamente al comenzar las Cortes de Zaragoza, en junio de 1518. Su puesto lo ocupó Gattinara . Laurent de Gorrevod, mayordomo de Carlos V, al duque de Saboya para pedirle su beneplácito en el nombramiento del Gran Canciller:

Mon tres redoubté seigneur, si tres humblement que fere puis a vostre bon grace me recommande.

Monseigneur, depuis six sepmaines en ca est avenu le trespas de feu monseigneur le chancellier de bourgoigne, que dieu pardoint. El le roy et messieurs de son conseil desiderans de pourveoir dung bon parsonnaige audit estat ont advisé demander monseigneur le president de bourgoigne messir mercurin de gattynaire pour le pourveoir dudit estat. A quoy jay tin main de mon pouvoir, desirant que les bon parsonnaiges vos subjectz fussent colloquez es lieux et maisons royales ou il vous puissent fere service cy apres. Et aloy depesché expressement ce courier pour aller querir ledit seigneur president messire mercurin. Vous ferez bien luy dire quelques bonnes parolles. A celle fin quil demeure tousiours en volunté de vous fere service comme vostre bon subject et serviteur et que son devoir porte, Ce dont je ne fais nulle doubte quil fera. De Sarragoce le xxiie de juillet 1518. Vostre tres humble et obeissant subject et serviteur Laurens de Gorrevod ${ }^{31}$.

Los consejeros de Maximiliano I habían impuesto su nombramiento para dirigir el Consejo del joven rey de Castilla y Aragón. Fue Maximiliano I y no Carlos quien le comunicó a Gattinara que había sido nombrado «Gran Canciller de todos los Reinos y dominios», indicándole que su principal obligación era convencer al rey para que se postulase como electo para el título de Rey de Romanos, es decir, ser designado sucesor al Imperio. Urgía mantener la continuidad de la Casa de Habsburgo al frente del Sacro Imperio Romano Germánico. El título de Rey de Romanos era una figura que permitía al emperador designar a su sucesor en vida del emperador evitando el riesgo de una elección imperial incierta. Mientras duró el enfrentamiento entre imperiales y borgoñones, la negativa del príncipe a interesarse por obtener dicha dignidad impedía garantizar la sucesión para la Casa de Habsburgo ${ }^{32}$.

A partir de ese momento el "erasmismo político" desapareció del entorno del rey. Durante el verano, la correspondencia de Erasmo cambió de tono, tanto que el editor de su correspondencia se ve obligado a precisar, en una nota a pie de página, que en las cartas escritas con posterioridad a la muerte del Canciller de Brabante nos hallamos ante un hombre que ha perdido su mundo. Sus cartas a los humanistas ingleses no dejan lugar a dudas, ya sea en una misiva a Cuthbert Tunstall («meus Cancellarius periit in Hispaniis: unde spei nostrae summa pendebat") ${ }^{33}$, Richard Pace

31 Bornate, "Historia Vitae", 270.

32 Manuel Rivero Rodríguez, "De la separación a la reunión dinástica: la Corona de Aragón entre 1504 y 1516", en La corte de Carlos V (Madrid: Sociedad Estatal para la Conmemoración de los Centenarios de Felipe II y Carlos V, 2000), 73-101..

${ }^{33}$ Lovaina 22 de octubre de 1518, Erasmo de Rótterdam, Opus Epistolarum, vol. III, no 866 (p. 424). 
("extincto cancellario nihil est quod sperem a nostris») ${ }^{34} \mathrm{o}$ William Warham («Habes tragoediam calamitatum mearum: ad quas et illud accessit, quod principis nostri Cancellarius in Hispanis diem suum obiit, unde spes omnis in his regionibus pendebat; unum enim hunc habebam ex cusimo faventem») $)^{35}$, los lamentos van más allá de la retórica que acompaña su intento de entrar al servicio de Enrique VIII de Inglaterra ayudado por sus amigos ingleses, presumiblemente Moro y Collet ${ }^{36}$.

El 8 de octubre de 1518 Gattinara prestó juramento en Zaragoza, en su toma de posesión exhortó a Carlos I para que solicitara la dignidad de Rey de Romanos por «la sola razón que el título del Imperio se ha juzgado como (medio) justísimo para conseguir todo el mundo, como aquello que consta haber sido ordenado por el propio Dios, predicho por los Profetas, predicado por los Apóstoles y por el mismísimo Cristo redentor nuestro». Unos días después se suspendió de empleo y sueldo a Erasmo de Rotterdam. Durante el viaje de la Corte de Carlos V desde Zaragoza a Barcelona, en los primeros meses de 1519, Gattinara discutió incansablemente con los cortesanos flamencos aún reticentes a aceptar que su señor fuera emperador. Los dos años que llevaban fuera de su patria les hacían sentir vértigo con la prodigiosa acumulación de estados que reportaban las coronas de Castilla y Aragón ${ }^{37}$. Aunque aceptaron plegarse a los deseos dinásticos de Maximiliano I, lo hicieron con poca determinación, aceptando un mal necesario. Esa abulia motivó a Gattinara para escribir su famoso memorial de Barcelona el 12 de julio de 1519, indicando cuales eran los deberes de un emperador, recordándole que ya no era un señor temporal cualquiera ${ }^{38}$.

En su discurso, Gattinara recogió algunos rasgos del mito histórico de la cultura política del gibelinismo, el emperador como cabeza de la Cristiandad destinado a reformar la Iglesia, y el monarca de la profecía joaquinista, el «emperador de los últimos tiempos», vinculando el nombre, Carlos, a Carlomagno. Las ideas que de forma constante aparecen se resumen en que Dios ha concedido a Carlos V la gracia de elevarlo por encima de todos los reyes, destinarlo a restaurar el Imperio de Carlomagno y dotarle de la responsabilidad de reducir al mundo bajo un sólo pastor, exaltar la fe y reformar la Cristiandad. De forma adyacente se incluye el viaje a Italia para ser coronado en Roma donde presidirá el Concilio que devuelva el orden a la Cristiandad:

Señor, pues que Dios creador os ha concedido la gracia de elevaros en dignidad por encima de todos los reyes y príncipes cristianos constituyendóos el mayor Emperador y rey que ha existido desde la división del Imperio hecha por Carlomagno vuestro predecesor, y encaminándoos derechamente a la Monarquía Universal para reducir al mundo bajo un solo Pastor, es una buena razón para que vuestra imperial y cesárea magestad para evitar el vicio de la ingratitud reconozca a su creador verdadero distribuidor de todos sus bienes,

\footnotetext{
${ }^{34}$ Lovaina 23 de octubre de 1518, Ibídem, no 877 (p. 425).

${ }^{35}$ Lovaina 24 de octubre de 1518, Ibídem, nº 893 (p. 431).

${ }^{36}$ Carta a Enrique VIII, Amberes 15 de mayo de 1519, Ibídem, no 964 (p. 578). Allen añade una nota explicativa que sitúa a Erasmo en el contexto de un hombre que ha perdido su mundo.

37 Vita del Gran Cancelliere Mercurino, ASV. FAG., mazzo 3, fols. 28-29.

${ }^{38}$ Fechado en Barcelona a 12 de julio de 1519, original en ASV. FAG., mazzo 8.
} 
a él rendirá condignas gracias y le atribuirá los debidos triunfos prescindiendo de toda ambición y vanagloria, por las cuales el enemigo de la naturaleza humana se esfuerza debilitar y arruinar a aquellos que son elevados a la más grande dignidad. Y así, dejando de lado las voluptuosidades y vicios que podrían distraer y repeler el ejercicio de las virtudes y buenas obras es necesario que Vuestra Majestad de todo corazón e intención se disponga al servicio, amor y temor de Dios y que sólo en Él pongáis todo vuestro fundamento ${ }^{39}$.

\section{BIBLIOGRAFÍA}

Aram, Bethany, La reina Juana: gobierno, piedad y dinastía (Madrid: Marcial Pons Historia, 2001)

Augustijn, Cornelis, Erasmo de Rotterdam : vida y obra (Barcelona: Crítica, 1990)

Baron, Hans, The Crisis of the Early Italian Renaissance: civic humanism and republican liberty in an age of classicism and tyranny (Princeton N.J.: Princeton University Press, 1955)

Bataillon, Marcel, «Erasmo et la chancellerie imperiale», Bulletin Hispanique, XXVI (1924), 29

Boone, Rebecca, «Claude de Seyssel's Translations of Ancient Historians», Journal of the History of Ideas, 61 (2000), 561 <http://dx.doi.org/10.2307/3654069>

Bornate, Carlo, «Historia vitae et gestorum per dominum magnum canellarium, con note, aggiunte e docu- menti», Miscelanea di Storia Italiana, 48 (1915), 233-558

Dickens, A.G., y W.R.D. Jones, Erasmus the reformer (London: Methuen, 2000)

Erasmo, Desiderio, Adagios del poder y de la guerra y teoría del adagio, ed. Ramón Puig de la Bellacasa Alberola (Barcelona: Pre-Textos, 2000)

Erasmo de Rotterdam, Opus Epistolarum / The complete letters of Erasmus, ed. Stanford Allen (Oxford: Clarendon Press, 1906)

Giesey, Ralph E., «Review: The Monarchy of France. by Claude de Seyssel», Renaissance Quarterly, 35 (1982), 490-91

\footnotetext{
${ }^{39}$ Preámbulo de la memoria escrita por Gattinara al emperador el 12 de julio de 1519 , folios 1 y $1 \mathrm{v}^{\mathrm{o}}$ del autógrafo conservado en ASV. FAG. mazzo 8, en la carpeta $n^{\circ} 10$.
} 
<http://dx.doi.org/10.2307/2861220>

Le Glay, Andre Joseph Ghislain, Correspondance de Maximilien I" et de Marguerite d'Autriche (Paris, 1839)

Hankins, James, The Cambridge Companion to Renaissance Philosophy, Renaissance Quarterly, 2007, lxi <http://dx.doi.org/10.1353/ren.0.0241>

Hexter, Jack H., More's Utopia: the Biography of an Idea, 1.a ed. (New York: Harper \& Row, 1965)

Huizinga, Johan, Erasmo (Barcelona: Salvat, 1989)

Kümin, Beat, «Political Culture in the Holy Roman Empire», German History, 27 (2009), 131-44

Lutero, Martín, Escritos políticos, ed. Joaquín Abellán (Madrid: Tecnos, 1986)

Mackay, Ruth, «Governance and Empire during the Reign of Charles V: A Review Essay Reviewed Work ( $\mathrm{s}$ ): El monasterio de San Jerónimo de Yuste by Francisco Javier Pizarro Gómez; The Empire of the Cities : Emperor Charles $\mathrm{V}$, the Comunero Revolt , and the Transformatio», Sixteenth Century Journal, 40 (2009), 769-79

More, Thomas, Utopia, ed. George M. Logan y Robert M. Adams (Cambridge: Cambridge University Press, 2002)

Pennington, Kenneth., The prince and the law, 1200-1600 : sovereignty and rights in the western legal tradition (University of California Press, 1993)

Press, Volker, «The Habsburg Court as Center of the Imperial Government», The Journal of Modern History, 58 (1986), S23-45 $<$ http://dx.doi.org/10.1086/243147>

Renaudet, Augustin, Préréforme et humanisme à Paris pendant les premières guerres d'Italie : 1494-1517 (Slatkine Reprints, 2011)

Rivero Rodríguez, Manuel, «De la separación a la reunión dinástica: la Corona de Aragón entre 1504 y 1516», La corte de Carlos V (Madrid: Sociedad Estatal para la Conmemoración de los Centenarios de Felipe II y Carlos V, 2000), pp. 73-101

—_ Gattinara, Carlos V y el sueño del Imperio (Madrid: Silex Ediciones, 2005)

Rosenfeld, Paul, «The provincial governors from the minority of Charles $\mathrm{V}$ to the 
revolt», Anciens Pays et Assemblées d'État, XVII (1959), 3-63

Skinner, Quentin, Los fundamentos del pensamiento político moderno. I (Fondo de Cultura Económica, 1985)

Skinner, Quentin., Visions of politics. Volume 1, Regarding method (Cambridge: Cambridge University Press, 2002)

Tracy, James, Holland under Habsburg rule, 1506-1566: the formation of a body politic (Berkeley: University of California Press, 1990)

Ullmann, Walter, Principios de gobierno y política en la edad media, ed. Graciela. Soriano de García-Pelayo, Madrid (Alianza Editorial, 1985)

Yoran, Hanan, Between utopia and dystopia: Erasmus, Thomas More, and the humanist Republic of Letters (Lexington Books, a division of Rowman \& Littlefield, 2010).

Zeller, Gaston, «Les rois de France candidats à l' Empire», en Aspects de la politique française sous l'ancien régime (Paris: PUF, 1964)

Recibido: 12 de julio de 2017

Aprobado: 30 de octubre de 2017 